\title{
O ENSINO DO PORTUGUÊS COMO SEGUNDA LÍNGUA PARA SURDOS: ESTRATÉGIAS DIDÁTICAS
}

\author{
Djair Lázaro de Almeida ${ }^{1}$ \\ Glaucia Ferreira Dias dos Santos ${ }^{2}$ \\ Cristina Broglia Feitosa de Lacerda ${ }^{3}$
}

\section{Resumo}

Historicamente, as dificuldades do aluno surdo em relação à aprendizagem da leitura e da escrita foram atribuídas a causas inerentes à surdez. Porém, atualmente, se tem o conhecimento de que essas dificuldades ocorrem por não se levar em consideração, durante o processo de ensino e de aprendizagem, de suas especificidades linguísticas. Dessa forma, a grande maioria dos surdos, jovens e adultos, não tiveram uma escolarização que respeitasse tais especificidades. Diante disso, este trabalho objetiva descrever e analisar estratégias pedagógicas para o ensino de português escrito como segunda língua, a partir da construção de conhecimentos em Libras, em oficinas para alunos surdos egressos das etapas de alfabetização da educação básica. As atividades das oficinas foram documentadas por meio de vídeo-gravações e de registro em diários de campo. Fundamentado nos pressupostos teóricos da abordagem histórico-cultural, o presente estudo focalizou a importância das relações entre pesquisadores e participantes surdos propiciadas pela linguagem, constituindo-se em espaço de comunicação, de formação e de constituição de sujeitos. Os resultados indicam que o uso

\footnotetext{
${ }^{1}$ Doutorando, Universidade Federal de São Carlos, Programa de Pós-Graduação em Educação Especial, Departamento de Educação. Endereço: Rodovia Washington Luís, km 235 - SP-310, CEP 13565-905, São Carlos - São Paulo - Brasil. Endereço eletrônico: djair_lazaro@yahoo.com.br.

${ }^{2}$ Professora de Educação Especial - Licenciatura na Universidade Federal de São Carlos - UFSCar. Endereço: Rodovia Washington Luís, km 235 - SP-310, CEP 13565-905, São Carlos - São Paulo - Brasil. Endereço eletrônico: glauciafdsantos@gmail.com

${ }^{3}$ Docente do Programa de Pós-Graduação em Educação Especial UFSCar Departamento de Educação. Endereço: Rodovia Washington Luís, km 235 - SP-310, CEP 13565-905, São Carlos - São Paulo - Brasil. Endereço eletrônico: cristinalacerda@uol.com.br
} 
de Libras como língua de instrução nesses espaços é fundamental para a construção de conceitos e para a aquisição de conhecimentos em leitura e escrita, assim como didáticas apropriadas e embasadas em recursos imagéticos favorecem as trocas dialógicas, facilitando a compreensão pelos sujeitos surdos.

Palavras-chave: Língua Portuguesa para Surdos; Estratégia Didática; Abordagem Bilíngue

\section{INTRODUÇÃO}

O processo de ensino-aprendizagem da linguagem escrita da língua majoritária como segunda língua para surdos é tema de reflexão por parte de muitos pesquisadores e de estudos orientados por diversas perspectivas teóricas. Historicamente, as dificuldades do aluno surdo em relação à aprendizagem da leitura e da escrita foram atribuídas a causas inerentes à surdez.

Porém, diversos estudos (FERNANDES, 2006; KARNOPP e PEREIRA, 2012) apontam que essas dificuldades são provenientes de uma educação que não atende a suas demandas linguísticas, uma vez que deve ser pautada na língua de sinais. Assim como o ouvinte que entra em contato com um idioma diferente de sua língua materna, o surdo toma como base os elementos da língua que mais domina para o entendimento da outra, aproximando-as e confrontando-as, para a construção do significado.

Dessa maneira, o ensino do português como segunda língua para surdos deve ser realizado com base em uma língua passível de compreensão - a língua de sinais, para que o esperado encontro entre as duas línguas seja usado com o fim de nortear essa aprendizagem, que "tem na L1 a base para a compreensão e significação dos processos socioculturais, históricos e ideológicos que perpassam a L2" ${ }^{4}$ (LODI, 2004, p. 31). Portanto, o aluno surdo não pode aprender o português no mesmo espaço dos falantes dessa língua, uma vez que as professoras de ouvintes conduzem as aulas atendendo ao grupo majoritário, que tem o português como língua materna. Para o aluno surdo, esse processo deve ser conduzido como ensino de segunda língua, pois "o letramento no português é dependente da constituição de seu sentido em língua de sinais" (FERNANDES, 2006, p. 122). Dessa forma, o domínio da Língua Brasileira de Sinais (Libras) pelos alunos surdos é fundamental para a construção do

\footnotetext{
${ }^{4} \mathrm{O}$ termo L1 refere-se à primeira língua do sujeito, com a qual se constroem as significações e a constituição de novos conceitos; já o termo L2 refere-se às outras línguas que ele poderá vir a aprender.
} 
conhecimento. Porém, a falta de contato com pares surdos, usuários de Libras, associada ao histórico de oralização a que essa população foi submetida, reflete a precariedade de acesso a essa língua, já que a maioria dos surdos é oriunda de famílias ouvintes, com pouco ou nenhum contato com a Libras, portanto, sem oportunidade para um adequado desenvolvimento da linguagem.

Tomando em consideração os resultados acadêmicos insatisfatórios de alunos surdos incluídos na rede regular de ensino, torna-se premente uma intervenção nesse campo, tendo em vista a aprendizagem da leitura e da escrita em Língua Portuguesa de maneira autônoma, ainda nas séries iniciais do Ensino Fundamental, garantindo, assim, uma aprendizagem consistente dos conteúdos escolares. No entanto, isso não tem ocorrido no espaço escolar no tempo regular. Por isso, abordar o ensino do português como segunda língua para sujeitos surdos é de suma importância e tem sido defendido por vários autores preocupados com essa realidade (LODI, 2004; PEIXOTO, 2006). Muitos surdos egressos da educação básica não tiveram a oportunidade de vivenciar o português como L2, não se alfabetizando satisfatoriamente. Ou ainda, grande parte deles circula pela Educação de Jovens e Adultos (EJA), muitas vezes adquirindo o diploma de ensino médio, sem poder dar continuidade a seus estudos, por não ter aprendido o suficiente para atender suas necessidades e as exigências sociais.

Apesar de a atual legislação assegurar como direito do aluno surdo um atendimento adequado (BRASIL, 2002; 2005), poucos são os locais no Brasil que têm experiência com a prática de ensino de português como segunda língua para essa parcela da população, em qualquer nível de ensino. Pela política educacional brasileira, a qual advoga pela inclusão e também pela recente oficialização da Língua Brasileira de Sinais (Libras), torna-se fundamental discutir estratégias didáticas que possam permitir o amplo letramento de alunos surdos no português escrito. Trata-se de um conhecimento novo que precisa ser construído também a partir das práticas que vêm sendo desenvolvidas por professores bilíngues e seus alunos surdos no cotidiano escolar.

Nessa perspectiva, o presente artigo objetiva descrever e analisar estratégias de ensino de português como segunda língua, utilizando a Libras como língua de instrução, em um ambiente não escolar, em oficinas para surdos que já passaram pelas etapas de alfabetização da educação básica, mas que não são proficientes em português escrito. Este trabalho visa, ainda, a conhecer melhor o papel da língua de sinais como língua mediadora da construção de 
conhecimentos sobre o português escrito, bem como a compreender os valores atribuídos a essas línguas, em ambientes de aprendizagem.

\section{A EDUCAÇÃO DE ALUNOS SURDOS}

A educação de surdos, em sua especificidade quanto ao processo de aquisição da leitura e da escrita em Língua Portuguesa, tem sido objeto de estudo entre muitos pesquisadores da área. As inadequadas condições de escolarização a que a maioria dos surdos é submetida colocam-se como o grande desafio a ser enfrentado. Nesse sentido, a questão deve ser abordada a partir de ações que visem a mudanças de concepção de língua e de linguagem, adotadas no ensino de português como segunda língua para surdos.

Com a publicação da Lei n. ${ }^{\circ} 10.436$ (BRASIL, 2002), que reconheceu a Libras como língua de comunicação e expressão das comunidades surdas brasileiras; e do Decreto n. ${ }^{\circ}$ 5.626 (Brasil, 2005), que previu a inserção de profissionais específicos para atuação na educação de surdos, várias ações têm sido cobradas da parte do poder público no sentido de atender adequadamente essa parcela da população. Nesse contexto, o momento atual apresenta uma intesificação nas discussões em torno de uma proposta bilíngue de educação.

Cabe lembrar que o objetivo da proposta bilíngue é de garantir ao aluno surdo um desenvolvimento cognitivo-linguístico compatível com o desenvolvimento de ouvintes da mesma faixa etária, a partir da língua de sinais e em convivência com seus pares surdos para a construção e a valorização da identidade surda e assegurar a aprendizagem da língua majoritária como segunda língua, na companhia harmoniosa dos ouvintes. Assim, o aluno surdo terá acesso a duas línguas: a língua de sinais e a língua do grupo majoritário.

Tal proposta educacional defende (...) que sejaensinada ao surdo a língua da comunidade ouvinte na qua lestá inserido, oral e/ou escrita tendo por base os conhecimentos adquiridos por rmeio da língua de sinais. Dessaforma, tal projeto de escolarização pressupõe que os educadores tenham domínio das línguas envolvidas, língua de sinais e a língua portuguesa, e o modo peculiar de funcionamento de cada uma delas em seus diferentes usos sociais, domínio fundamental para possibilitar o acesso dos surdos aos conhecimentos de mundo em ambas as línguas (LACERDA e LODI, 2014 p. 12).

Vale destacar que, apesar de assegurado o direito a uma educação que atenda a suas demandas linguísticas, nem todos os alunos surdos têm acesso à educação bilíngue. Isso, 
porque a educação de surdos é marcada por diversas ações muitas vezes ineficientes para atender a suas especificidades, pois é comum que, ao final da escolarização básica, esses alunos não sejam capazes de ler e de escrever satisfatoriamente, ou de ter um domínio adequado dos conteúdos acadêmicos (LACERDA, 1998). Tal cenário é reflexo de um processo de educação que não atende às singularidades dos alunos surdos, os quais acabam sendo promovidos mesmo sem o desenvolvimento de habilidades e competências previstas para os conteúdos acadêmicos de cada etapa de escolarização. Nessas condições, muitos alunos surdos, após anos inseridos na rede regular de ensino, recebem a certificação de conclusão das etapas educacionais, sem, no entanto, terem adquirido os conhecimentos mínimos exigidos para tanto.

Pesquisas acadêmicas que analisam a inclusão de alunos surdos em contextos de escolas regulares, sem nenhum aparato pressuposto para uma educação bilíngue (GÓES e TARTUCI, 2012), exemplificam a realidade vivenciada por esses alunos. Segundo as autoras citadas, em um contexto escolar nos anos iniciais da educação básica com crianças surdas incluídas, observa-se que, apesar dos esforços por parte das professoras para um atendimento individualizado (buscando posicionar-se melhor em sala, falar pausadamente ao se dirigir aos alunos surdos), quando comparadas ao restante da turma, essas crianças acabam ficando em desvantagem em relação aos conteúdos desenvolvidos, devido à falta de uma língua em comum para o estabelecimento de diálogos.

Para que os alunos surdos possam se apropriar integramente dos conteúdos ministrados em sala de aula, é preciso respeitá-los em suas demandas linguísticas. Dessa maneira, torna-se necessário que esses alunos tenham acesso aos conteúdos escolares em Libras, tendo em vista que essa é a língua passível de aquisição e que pode melhor mediar a construção de novos conhecimentos. Isto se dá porque a língua de sinais, por utilizar o canal visogestual, é a únic amodalidade de linguagem plenamente acessível ao surdo, favorecendo seu desenvolvimento e auxiliando-o em sua constituição de sujeito. Assim, a língua de sinais deve ser incorporada às praticas pedagógicas para um desenvolvimento integral do aluno surdo, levando em conta a sua particularidade linguística e, portanto, o acesso à cultura do grupo no qual está inserido (Lacerda; Lodi, 2014).

Apesar de a língua de sinais ser considerada a língua natural dos surdos, não basta ser surdo para adquiri-la, ou seja, sua apropriação não é inerente à condição de surdez. Para o surdo se tornar usuário de Libras, é necessário que esteja inserido em ambientes propícios à 
troca dialógica de experiências com outros falantes dessa língua. Considerando que cerca de 90\% dos surdos nascem em famílias de ouvintes, as quais fazem uso de uma língua sem nenhuma significação para eles (FERNANDES, 2006), é comum que os surdos tenham um desenvolvimento tardio de linguagem e de outras funções mentais superiores, pois há uma grande redução das trocas simbólicas como meio social, já que não há a mediação de uma língua para estabelecer esse diálogo. Porém, vale destacar que, mesmo que os surdos tenham acesso tardio à língua de sinais, ainda será nessa língua que grande parte deles se apoiará para a aquisição dos conteúdos curriculares, principalmente, os relacionados à leitura e à escrita (GUARINELLO, 2006).

Segundo Vygotsky (2008), a linguagem é um evento social que se desenvolve a partir das interações sociais, nas relações interpessoais. É, portanto, no processo de constituição da linguagem, e por seu intermédio, que os conceitos são construídos e os significados e sentidos são apropriados. Assim, as funções mentais superiores são construídas ao longo da história social do sujeito, em sua relação com o mundo. Nesse sentido, o conhecimento só é possível por meio da linguagem, que organiza o pensamento. Dessa forma, ao iniciar sua trajetória escolar com uma defasagem na linguagem, a criança enfrenta dificuldades quanto à aquisição dos conhecimentos escolares, apresentando desvantagem em relação aos demais alunos.

Isso posto, é fundamental que a criança surda tenha contato com a língua de sinais o mais cedo possível, uma vez que essa é a única capaz de propiciar a formação dos surdos como sujeitos plenos, ampliando suas relações com o mundo. De acordo com Bakhtin (2009), a língua é a materialização da linguagem humana, possibilitando a reconstrução do mundo para além das referências imediatas e efêmeras. Portanto, é necessário proporcionar condições linguísticas, sociais e culturais particulares para que os surdos se apropriem da linguagem, a partir de práticas e contextos concretos vivenciados por usuários da mesma língua.

\subsection{O Ensino de Português como segunda língua (L2) e o letramento}

Apesar de o aluno surdo apropriar-se dos saberes por meio da língua de sinais, que deve ser incorporada às práticas educacionais como direito linguístico, também é de seu direito a aprendizagem do português escrito, uma vez que as mediações simbólicas que regem as relações do homem com os conhecimentos adquiridos historicamente são efetivadas, em grande parte, pelo registro escrito. Assim, o não transitar proficientemente pela língua escrita 
invibializa o acesso a esses conhecimentos e os encontros com os diferentes discursos que aí circulam. O surdo, como um cidadão brasileiro, tem o direito de se apropriar da língua majoritária na modalidade escrita, caso contrário, dele seria excluído o direito de cidadania. A própria legislação que garante Libras como língua da comunidade surda, assegura que esta não substituirá a modalidade escrita da Língua Portuguesa (BRASIL, 2002).

As crianças surdas não possuem problemas cognitivos que as impeçam de se apropriarem dos conteúdos do português escrito. Entretanto, muitos surdos têm dificuldades em se tornarem leitores e escritores autônomos em português, mesmo sendo submetidos a sistemas educacionais que adotem filosofias pensadas para a educação de surdos, como no caso do oralismo e da comunicação total, pois nelas o processo de leitura e de escrita é ensinado a partir da relação com a oralidade, relacionando fonemas a grafemas (FERNANDES, 2006).

O ensino de português para alunos surdos deve ser desenvolvido do mesmo modo como o ensino de uma língua estrangeira a qualquer pessoa. $\mathrm{O}$ surdo precisa aprender a ler e a escrever em uma língua na qual não domina a fala. Nesse sentido, Peixoto (2006, p. 209) afirma que

\footnotetext{
A condição de segunda língua que o Português tem na vida do surdo promove nesse sujeito um estranhamento semelhante ao que nós, ouvintes, temos quando nos deparamos com uma língua estrangeira. Interpretar ou produzir uma escrita estranha à própria língua confronta nossa organização de linguagem e nosso conhecimento gramatical, exigindo uma produção de novas significações que só conseguiremos construir tendo como base a nossa língua materna.
}

Segundo Karnopp e Pereira (2012), as pesquisas sobre essa temática apontam que as crianças surdas que possuem contato com a língua de sinais, desde que começam sua vida escolar, utilizam-se de estratégias linguísticas evidenciando o uso das duas línguas. Portanto, o ensino da Língua Portuguesa a alunos surdos deve se dar a partir da construção de conhecimentos em Libras, de maneira significativa e contextualizada, buscando, inicialmente, a significação do português em seus diferentes contextos e; em seguida, partir para a aprendizagem da estrutura formal, pois, estando expostos à nova língua, esses alunos vão criando hipóteses em relação à sua gramática.

Nesse sentido, Fernandes (2006, p. 132-133), com base em diversos pesquisadores, afirma que 
a língua escrita pode ser plenamente adquirida pelos surdos se a metodologia empregada não enfatizar a relação letra-som como pré-requisito, mas recorrer, principalmente, a estratégias visuais, prioritariamente pautadas na língua de sinais, similares metodologicamente àquelas utilizas usualmente no ensino de segunda língua para ouvintes.

Nessa ótica, a autora faz uma distinção entre alfabetização e letramento, na prática pedagógica de alunos surdos, uma vez que o processo compreende a passagem de uma língua não alfabética para uma língua alfabética. Assim, aponta que as práticas tradicionais de alfabetização não beneficiam os alunos surdos, pois são pautadas na oralidade e na associação entre fonema e grafema, com ênfase na aprendizagem da codificação e decodificação de letras, números, sons, palavras. O ensino embasado em tal prática gera alunos reprodutores de textos mecânicos, sem autonomia na leitura e na escrita, ou seja, alunos que dificilmente se relacionarão com o texto de forma global e significante. Sob essas condições, o ensino de leitura e escrita para alunos surdos deve ser pautado na aquisição significativa de letramento como um conjunto de práticas sociais que utilizam a escrita de acordo com contextos e objetivos específicos. Por tal ótica, letramento refere-se às práticas sociais e aos eventos em que tais práticas são colocadas em ação (SOARES, 2002).

Assim, os surdos, partindo da vivência com a língua, formulam hipótese em relação à escrita e às suas normas gramaticais. De acordo com Fernandes (2006), o letramento para surdos envolve reflexão sobre duas línguas, portanto, aprender português decorre da significação que essa língua assume nas práticas sociais, logo, depende da constituição de sentido na língua de sinais. Para Fernandes (2006, p. 134), “a língua de sinais exerce função semelhante à oralidade no aprendizado da escrita pelos surdos, possibilitando a internalização de significados, conceitos, valores e conhecimentos" que medeiam "a apropriação imagética do sistema de signos escritos". Assim, não é necessário que o surdo consiga falar e/ou ouvir para aprender a modalidade escrita da Língua Portuguesa.

Conforme apresentado até o momento, conclui-se que para o processo de ensino e aprendizagem de alunos surdos é preciso que haja ambientes de trocas dialógicas, em língua de sinais, para a construção de conhecimento, garantindo, assim, o sucesso escolar desses alunos, principalmente na aquisição de leitura e de escrita. Guarinello (2006; 2007), em seus estudos, aponta como a mediação de um adulto bilíngue contribui para o sucesso desse processo. 


\begin{abstract}
As atividades com a escrita devem privilegiar a dimensão discursiva da linguagem, envolvendo a interação professor/aluno; o professor deve ser o orientador, o mediador, o parceiro e o cúmplice na construção dessa língua, deixando o sujeito surdo livre paraformular hipóteses até que chegue à escrita convencional socialmente valorizada (2006, p. 365).
\end{abstract}

A partir de atividades significativas de construção de textos, com negociação entre o professor e alunos surdos, por meio da língua de sinais, o mediador pode realizar um processo coletivo de retextualização, com a finalidade de adequar o texto produzido às normas formais da gramática, sem grandes interferências na produção dos alunos. Com isso, há uma interação entre o produtor e o leitor do texto na negociação de sentido, sendo que a coesão e a coerência são construídas conjuntamente. Considerando o exposto, para o ensino de leitura e de escrita, deve-se ter em mente que

o domínio do português escrito só acontecerá por rmeio de seu uso constante, assim, os surdos, como os ouvistes, precisam ter acesso aos diferentes tipos de texto escrito. Além disso, o trabalho com a escrita deve partir do que esses indivíduos já possuem, ou seja, a língua de sinais, pois é essa a língua que dará toda a base linguística para aprendizagem de qualquer língua. (GUARINELLO, 2007, p. 142)

\title{
2.2 A pedagogia visual
}

Seguindo as tendências da chamada Sociedade da Visualidade, a Pedagogia Visual tenta acompanhar as mudanças e os avanços tecnológicos dessa sociedade nas trilhas dos discursos imagéticos, impondo aos indivíduos para que absorvam conhecimentos de diferentes maneiras e formas (CAMPELLO, 2007).

Frente a essa realidade, impõe-se à educação de surdos organizar uma pedagogia que contemple a visualidade, principal via de acesso às informações dessa parcela da população. Assim, vídeos, imagens, figuras, gráficos tão presentes no cotidiano da vida moderna, além das expressões faciais e corporais devem ser explorados e incorporados nos discursos que circulam no ambiente escolar. Segundo Lacerda, Santos e Caetano (2013, p. 187), "uma imagem pode evocar a compreensão de vários elementos de um determinado tempo histórico e, nesse sentido, evocar significados sem a presença de qualquer texto escrito". Observa-se que o processo de significação para o surdo, muitas vezes, se dá somente a partir das imagens que o rodeiam, constituindo-se nos únicos conhecimentos prévios, pela privação de uma 
língua. Nesse contexto, o professor, valendo-se da semiótica imagética, pode explorar as linguagens não verbais para contextualizar atividades, tornando-as significativas aos alunos e, por meio delas, introduzir conceitos que mais adiante poderão ser discutidos e aprofundados pela mediação de uma língua constituída (preferencialmente a língua de sinais, quando o aluno surdo ainda não domina o português escrito).

Nessse enfoque, o professor pode valer-se, em sala de aula, da língua de sinais e da pedagogia visual para explorar previamente os conteúdos e os conceitos complexos. Para Campello (2007, p. 113), “com características viso-espaciais, a LSB ${ }^{5}$ inscreve-se no lugar da visualidade e, sem dúvida, encontra na imagem uma grande aliada às propostas educacionais e às práticas sociais".

\section{PROCEDIMENTO METODOLÓGICO}

Para o desenvolvimento desta pesquisa, realizou-se o acompanhamento de uma Oficina de Língua Portuguesa, na modalidade escrita, como segunda língua para surdos. Os participantes da oficina, surdos (jovens e adultos) que já concluíram as etapas de alfabetização da educação básica, não tiveram, durante esse processo, português como segunda língua, intérprete ou qualquer atenção especial, apresentando domínio restrito do português escrito e dificuldades para a leitura e para a construção de pequenos textos. As oficinas foram conduzidas e/ou apoiadas por pesquisadores, doutorandos do Programa de Pós-graduação em Educação Especial da UFSCar, ouvintes bilíngues em parceria com outros pesquisadores da área de surdez. A língua de instrução das atividades foi a Libras, uma vez que as oficinas ocorreram em uma perspectiva bilíngue, a qual concebe a língua de sinais como a forma de acesso aos conhecimentos, sendo de fundamental importância para os processos de linguagem e aprendizagem dos sujeitos surdos.

Este estudo fundamentou-se nos pressupostos teóricos da abordagem históricocultural, que se preocupa não em apenas descrever a realidade, mas em explicá-la (FREITAS, 2009). Nesse sentido, Vygotsky (1998) aponta que estudar historicamente um fenômeno é investigá-lo em seu processo de mudança, o que remete a uma abordagem dialética. Para Freitas (2009, p. 6), a

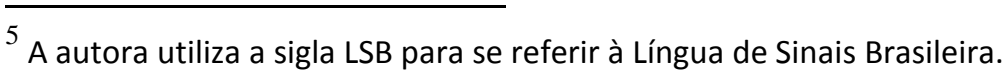




\begin{abstract}
abordagem dialética permite compreender a pesquisa nas ciências humanas como uma relação entre sujeitos possibilitada pela linguagem, relação essa provocadora de mútuas transformações em seus integrantes. A situação de pesquisa torna-se dessa forma uma produção de linguagem e uma esfera social de circulação de discursos, portanto, se apresenta como um espaço educativo de comunicação e constituição de sujeitos. Se pensarmos essa pesquisa no ambiente escolar, no trabalho com alunos e professores é possível aindaconsiderá-lacomo um espaço de formação.
\end{abstract}

Assim, a vídeo-gravação mostrou-se como uma técnica adequada para tais fins, uma vez que possibilita observar a realidade apresentando-se, em processo, revelando as interações e as práticas durante as oficinas, propiciando ao pesquisador uma visão ampla dos processos e dos produtos sociais nesse espaço.

\title{
3.1 Procedimentos de coleta de dados
}

As atividades da oficina foram documentadas por meio de vídeo-gravações (no período médio de uma hora e meia por semana, durante o primeiro semestre de 2013, totalizando13 encontros), por entendê-las como o instrumento mais adequado para o registro de uma atividade visogestual para a posterior análise, além de registros em diários de campo. Os diários de campo foram utilizados com o intuito de caracterizar e catalogar os encontros. O foco das análises assentou-se nas estratégias de ensino de Língua Portuguesa como segunda língua a surdos que frequentaram a oficina.

As filmagens foram realizadas com o uso de duas câmeras: uma focada nos participantes surdos, que permanecia estática na maior parte do tempo; e outra que filmava os pesquisadores bilíngues, e era movimentada de acordo com a localização do enunciador no espaço, com a finalidade de capturar todo o diálogo presente (ver FIGURAS 1, 2 e 3). É importante destacar que, devido às condições físicas do espaço e da distribuição do mobiliário, houve momentos em que não foi possível registrar todos os diálogos efetuados, pois os participantes enunciavam simultaneamente de três ou mais locais distintos da sala (um pesquisador explicava um conteúdo usando a lousa, por exemplo, enquanto o outro se encontrava mais próximo aos surdos), impossibilitando a filmagem de todos. Embora tenha sido solicitada aos pesquisadores uma atenção a esse respeito, essa instrução não foi reforçada a todo o momento, para não atrapalhar a fluidez do encontro e das práticas didáticas. 
Apresentamos, a seguir, a Fig. 1, representando o mapa da sala das oficinas, com a disposição dos mobiliários e equipamentos.

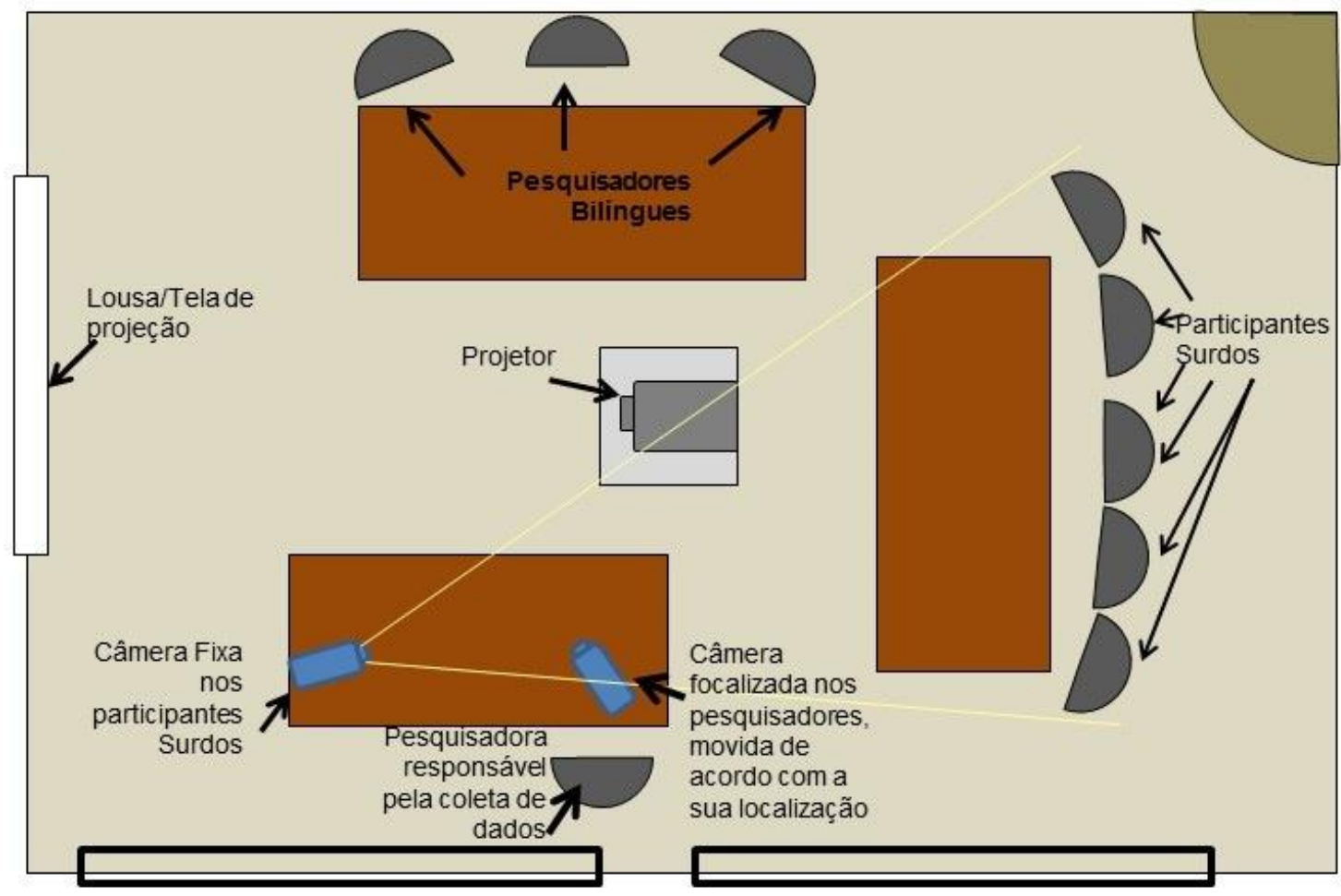

(Fonte: Pesquisadores)

As Fig. 2 e 3 trazem, respectivamente, as imagens da câmera que focalizava os participantes surdos e os pesquisadores bilíngues.

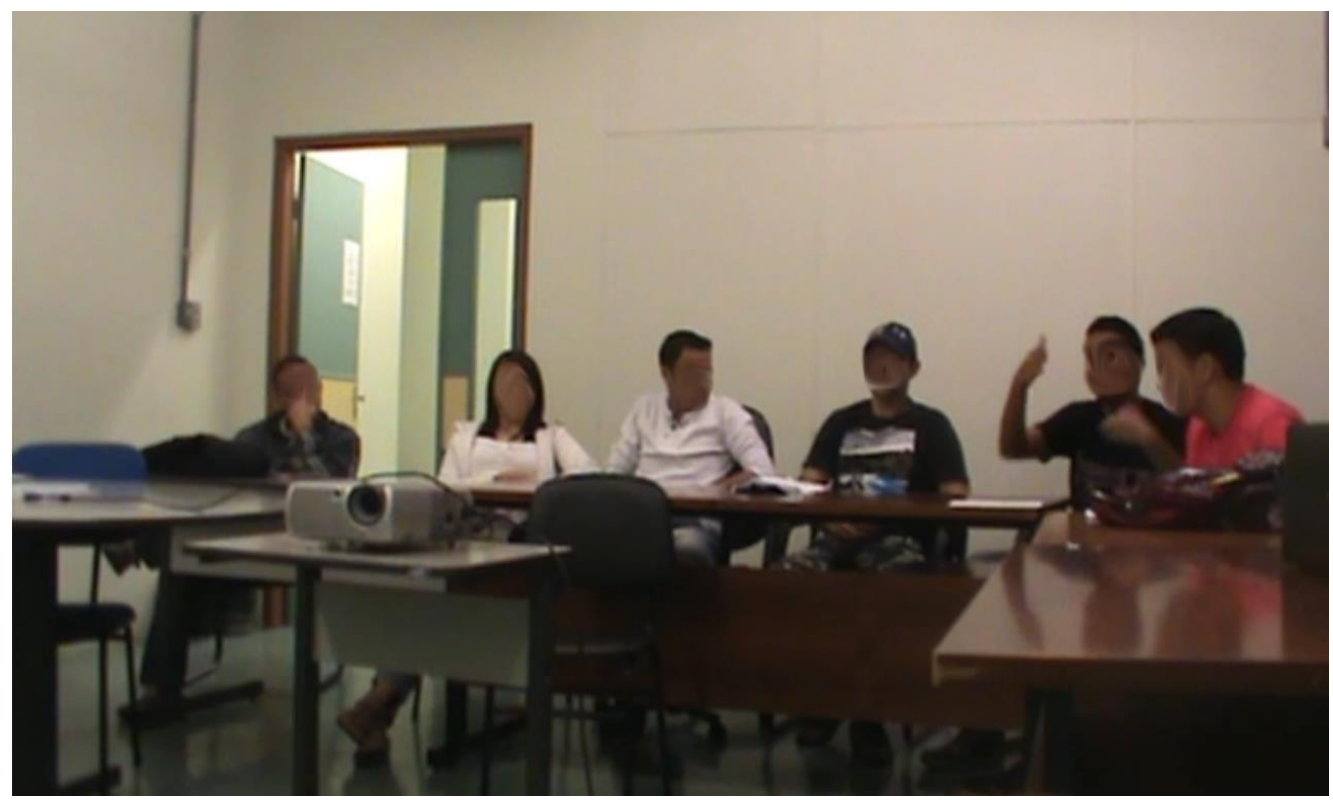

(Fonte: Pesquisadores) 


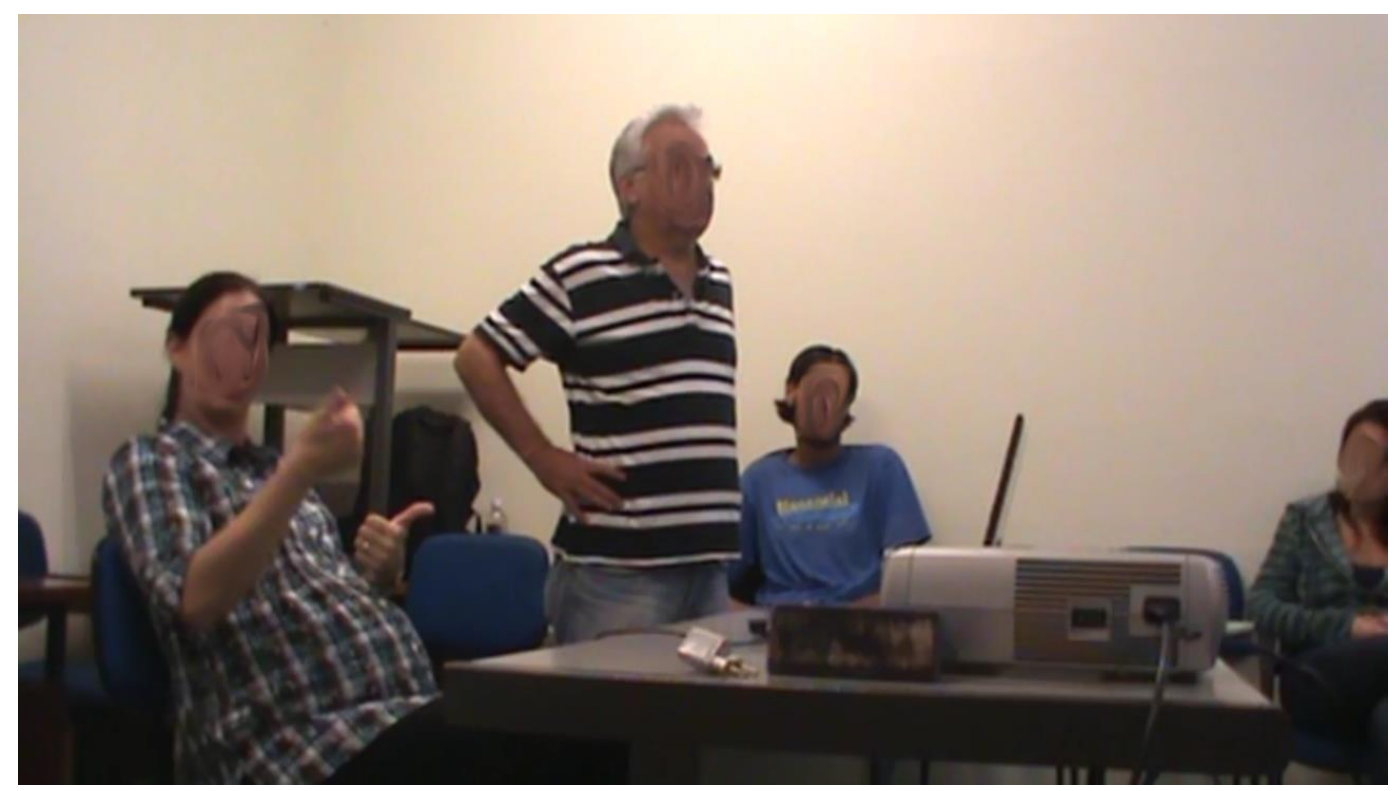

(Fonte: Pesquisadores)

O presente estudo foi submetido à avaliação do Comitê de Ética para pesquisa em seres humanos da Universidade Federal de São Carlos (UFSCar). Para concordar com a gravação, os participantes da pesquisa assinaram um termo de consentimento livre e esclarecido apresentado aos alunos surdos, tanto em português escrito quanto em Libras.

\subsection{Critérios para análise dos dados}

A análise dos dados foi realizada a partir da categorização dos encontros, separados de acordo com cada objetivo pedagógico principal, estratégias utilizadas e atividades desenvolvidas, que poderiam durar mais de um encontro. Em seguida, foram escolhidas atividades, dentro das categorias estabelecidas, para exemplificar as estratégias pedagógicas utilizadas. Tendo em vista que as estratégias pedagógicas se manifestavam no conjunto do desenvolvimento da atividade, optou-se por trazer uma descrição sistematizada delas, e não a transcrição de um trecho. Para analisar algumas das práticas pedagógicas desenvolvidas nesse período, foram escolhidos dois momentos: as construções de novos conceitos e os momentos de escrita coletiva. 


\subsection{Contextualização das oficinas}

O termo oficina, aqui empregado, objetiva fazer a diferenciação entre os trabalhos realizados nesses termos, e os realizados em salas de aula comum, uma vez que esse espaço não se responsabiliza por um ensino formalizado. Santos (2007), com base nos estudos de Souza Neto (2005), aponta que oficina é um espaço onde se exerce um ofício, com pessoas compartilhando as mesmas experiências e com possibilidade de adquirir novos conhecimentos e habilidades. Os surdos participantes das Oficinas de Língua Portuguesa pertencem à mesma comunidade e possuem um limitado conhecimento dessa língua. Assim, participam desses espaços para o desenvolvimento dos conhecimentos nessa língua por meio da interação e de trocas com seus pares. Os surdos procuraram a oficina para melhorar a proficiência em português em função das demandas sociais (ambiente de trabalho, escola, família, ingresso no ensino superior).

As oficinas de Língua Portuguesa tiveram início no ano de 2011, a partir da demanda da própria comunidade surda da cidade que apresentava grande interesse em aprofundar seus conhecimentos nessa língua, uma vez que os surdos sentiam-se limitados devido ao processo escolar a que foram submetidos, o qual não atendia às necessidades linguísticas (como assegura a atual legislação).

Na sequência, a tabela 1 mostra uma caracterização geral dos participantes surdos que frequentaram as oficinas durante o período acompanhado, trazendo nomes fictícios para preservação das respectivas identidades.

\begin{tabular}{l|l|l|l|l|l|l}
\multicolumn{2}{l}{ Tab. 1:Participantes Surdos } \\
\hline Nome & $\begin{array}{l}\text { Faixa } \\
\text { etária }\end{array}$ & Frequência & Escolarização & $\begin{array}{l}\text { Fase da } \\
\text { perda } \\
\text { auditiva }\end{array}$ & $\begin{array}{l}\text { Conhecimento } \\
\text { em Libras } \\
\text { (inicial)* }\end{array}$ & $\begin{array}{l}\text { Conhecimento } \\
\text { em Português } \\
\text { escrito } \\
\text { (inicial)* }\end{array}$ \\
\hline Miguel & 27 & $\begin{array}{l}\text { Desde o } \\
\text { início; alta } \\
\text { frequência. }\end{array}$ & $\begin{array}{l}\text { Ensino Médio } \\
\text { Completo }\end{array}$ & $\begin{array}{l}\text { Pré- } \\
\text { linguística }\end{array}$ & $\begin{array}{l}\text { Bom } \\
\text { conhecimento }\end{array}$ & $\begin{array}{l}\text { Pouco } \\
\text { conhecimento }\end{array}$ \\
\hline Denis & 13 & $\begin{array}{l}\text { Desde o } \\
\text { primeiro } \\
\text { semestre de } \\
\text { 2012; alta } \\
\text { frequência. }\end{array}$ & $\begin{array}{l}8^{\circ} \text { ano do } \\
\text { Ensino } \\
\text { Fundamental } \\
\text { em uma } \\
\text { escola } \\
\text { bilíngue }\end{array}$ & $\begin{array}{l}\text { Pré- } \\
\text { linguística }\end{array}$ & $\begin{array}{l}\text { Pouco } \\
\text { conhecimento }\end{array}$ & $\begin{array}{l}\text { Conhecimento } \\
\text { básico }\end{array}$ \\
\hline
\end{tabular}




\begin{tabular}{|c|c|c|c|c|c|c|}
\hline Dalton & 13 & $\begin{array}{l}\text { Desde o } \\
\text { primeiro } \\
\text { semestre de } \\
2012 ; \text { alta } \\
\text { frequência. }\end{array}$ & $\begin{array}{l}8^{\circ} \text { ano do } \\
\text { Ensino } \\
\text { Fundamental } \\
\text { em uma } \\
\text { escola } \\
\text { bilíngue }\end{array}$ & $\begin{array}{l}\text { Pré- } \\
\text { linguística }\end{array}$ & $\begin{array}{l}\text { Pouco } \\
\text { conhecimento }\end{array}$ & $\begin{array}{l}\text { Conhecimento } \\
\text { básico }\end{array}$ \\
\hline Wilson & 30 & $\begin{array}{l}\text { Desde o } \\
\text { Segundo } \\
\text { semestre de } \\
\text { 2012; alta } \\
\text { frequência. }\end{array}$ & $\begin{array}{l}\text { Dado } \\
\text { desconhecido }\end{array}$ & $\begin{array}{l}\text { Pré- } \\
\text { linguística }\end{array}$ & $\begin{array}{l}\text { Pouco } \\
\text { conhecimento }\end{array}$ & $\begin{array}{l}\text { Pouco } \\
\text { conhecimento }\end{array}$ \\
\hline Janaína & 17 & $\begin{array}{l}\text { Desde o } \\
\text { primeiro } \\
\text { semestre de } \\
2013 ; \text { alta } \\
\text { frequência. }\end{array}$ & $\begin{array}{l}1^{\circ} \text { ano do } \\
\text { Ensino Médio } \\
\text { em uma } \\
\text { escola regular } \\
\text { (sem } \\
\text { intreprete) }\end{array}$ & $\begin{array}{l}\text { Perda } \\
\text { gradual a } \\
\text { apartir dos } \\
9 \text { anos de } \\
\text { idade }\end{array}$ & $\begin{array}{l}\text { Pouco } \\
\text { conhecimento }\end{array}$ & $\begin{array}{l}\text { Conhecimento } \\
\text { intermediário }\end{array}$ \\
\hline Wesley & 30 & $\begin{array}{l}\text { Desde o } \\
\text { início; } \\
\text { baixa } \\
\text { frequência. }\end{array}$ & $\begin{array}{l}\text { Ensino } \\
\text { Fundamental } \\
\text { Completo }\end{array}$ & $\begin{array}{l}\text { Pré- } \\
\text { linguística }\end{array}$ & Fluente & $\begin{array}{l}\text { Pouco } \\
\text { conhecimento }\end{array}$ \\
\hline
\end{tabular}

*Dados observados (Fonte: Pesquisadores)

Dentre os participantes citados, Miguel, Denis, Dalton, Janaína e Wilson foram aqueles que realmente frequentaram as oficinas. O participante Wesley também frequentou as oficinas com certa regularidade, porém, como sua assiduidade foi baixa, sua participação não foi computada. Os demais participantes compareciam apenas esporadicamente. Com exceção de Denis, Dalton e Janaína, os demais participantes não frequentavam mais a escola.

Nenhum dos participantes teve acesso a um modelo escolar que atendesse as suas demandas durante a fase de alfabetização, em consequência, nenhum apresenta o domínio da Língua Portuguesa na modalidade escrita. Entretanto, Denis e Dalton, que são irmãos, frequentam há aproximadamente um ano em uma escola comum a proposta bilíngue, nos anos finais do ensino fundamental, recebendo, portanto, conhecimentos relativos à Língua Portuguesa como segunda língua, ministrada por professor bilíngue com domínio de Libras, favorecendo uma melhor evolução do que aquela apresentada por seus pares, durante o desenvolvimento das oficinas.

Como a oficina não se organiza de maneira semelhante à educação regular, não há a utilização de avaliações formais no método de ensino, cuja avaliação e planejamentos são feitos processualmente de acordo com as respostas dos participantes, durante o encontro. Dessa maneira, não há registros formais do conhecimento em português que todos participantes apresentavam no momento em que começaram a frequentar as oficinas. 
Com exceção de Janaína, os demais participantes ficaram surdos no período prélinguístico de seu desenvolvimento. Isso fez com que Janaína apresentasse um melhor conhecimento em português, pois ouvia normalmente até os nove anos de idade, e foi perdendo a audição gradualmente. Pelo fato de possuir alguns resquícios auditivos, ela desenvolveu a linguagem a partir do português oral. Entretanto, observa-se que a aluna apresenta dificuldades na significação dos conceitos, demonstrando, assim como os demais, uma cristalização do uso do português, de forma mecânica, sem o entendimento de diferentes significados. Pelo recente contato com a Libras, Janaína apresentava um conhecimento restrito dessa língua, motivo pelo qual, para a construção de conceitos, interagia mais com os pesquisadores do que com os companheiros surdos, fazendo uso do português oral.

Outra observação relevante é em relação aos conhecimentos em Libras por parte dos participantes. No início da oficina, poucos apresentavam um bom conhecimento em Libras, fator limitante para a comunicação com eles e entre eles. Entretanto, com a interação e as trocas propiciadas pelos encontros, observou-se uma melhora nos conhecimentos e utilização da língua de sinais.

A tabela abaixo apresenta um panorama dos pesquisadores que participaram da oficina de língua portuguesa.

Tab. 2:Pesquisadores

\begin{tabular}{|c|c|c|}
\hline Nome & Escolarização & $\begin{array}{ll}\text { Conhecimento } & \text { em } \\
\text { Libras (inicial) } & \end{array}$ \\
\hline Luna & $\begin{array}{l}\text { Doutoranda em } \begin{array}{l}\text { Educação } \\
\text { graduada em Fonoaudiologia }\end{array} \\
\text { Especial; }\end{array}$ & Fluente \\
\hline Milene & Graduada em Fonoaudiologia & Fluente \\
\hline Adriano & Graduando em Letras & Fluente \\
\hline Davi & $\begin{array}{llll}\begin{array}{l}\text { Doutorando em } \\
\text { graduado em Letras }\end{array} & \text { Educação } & \text { Especial; } \\
\end{array}$ & $\begin{array}{l}\text { Conhecimento } \\
\text { intermediário }\end{array}$ \\
\hline Nome & Escolarização & $\begin{array}{l}\text { Conhecimento } \\
\text { Libras (inicial) }\end{array}$ \\
\hline Glaucia & Graduanda em Educação Especial & $\begin{array}{l}\text { Conhecimento } \\
\text { intermediário }\end{array}$ \\
\hline
\end{tabular}

Os encontros foram coordenados pelas pesquisadoras Luna e Milena, por serem bilíngues e terem experiência com atividades relacionadas às oficinas. Entretanto, os demais pesquisadores acompanharam as oficinas, participando do planejamento das atividades e da produção de material. 
As oficinas não seguiam uma rotina fixa, pois suas atividades eram determinadas pelas respostas que os participantes surdos apresentavam. Por não se caracterizar em um ambiente escolar formal não houve uma preocupação em cumprir metas curriculares, e assim, uma dada atividade poderia se desdobrar em vários encontros, ou ainda, um tema poderia ser tratado em um único encontro. Não houve pressa em se cumprir um cronograma estabelecido, priorizando, dessa forma, a apropriação do conteúdo por parte dos participantes surdos, ao invés de satisfazer metas estabelecidas para um determinado espaço de tempo. Tal variação ocorreu de acordo com a evolução da atividade proposta e o aproveitamento dos participantes.

Durante as oficinas foram utilizados computador, projetor, lousa, mesas e cadeiras, conforme mostrado anteriormente na figura 1. Os participantes também utilizavam materiais escolares próprios ou emprestados pelos pesquisadores, para anotarem as atividades solicitadas e/ou as que achavam pertinentes.

As atividades realizadas nas oficinas, baseadas em vídeos e narrativas em Libras, seguidas de trabalho de leitura e escrita em português, foram planejadas de acordo com os anseios e as dificuldades dos participantes surdos, relacionando a temática desenvolvida de maneira contextualizada, para facilitar o entendimento e a significação. O princípio norteador do fazer da oficina consistiu em atividadesde leitura para acesso e ampliação dos conhecimentos da Língua Portuguesa, cujas atividades de escrita foram conduzidas de forma a aproveitar os conhecimentos construídos pela leitura e pelas trocas dialógicas entre todos os participantes. Todos os debates, dúvidas e processo de interpretação da leitura foram negociados em Libras, buscando-se uma compreensão satisfatória dos textos lidos para avançar nas atividades. Nesse sentido, foram incentivadas as trocas, as perguntas, as discussões de modo que os participantes se posicionassem ativamente no processo de aprendizagem, tornando-a significativa.

\section{ANÁLISE DOS DADOS}

Respondendo às propostas da educação bilíngue para surdos, a presente pesquisa configurou-se como oficina de Língua Portuguesa como segunda língua, por meio de um 
trabalho com narrativa de aventura, a partir do livro As sete viagens de Simbad, o marujo ${ }^{6}$. Visando à análise de práticas pedagógicas desenvolvidas nas oficinas, elegeram-se dois momentos: a construção de novos conceitos e a escrita coletiva. A escolha dos dois episódios para análise recaiu na importância das relações entre pesquisadores e participantes surdos, propiciadas pela linguagem e estimuladoras de transformações, constituindo-se em um espaço de comunicação, de formação e de constituição de sujeitos.

\subsection{A construção de conceitos - Descrição do episódio}

Durante as oficinas, pesquisadore se participantes surdos interagiam em dinâmicas nas quais circulavam discursos e se produzia linguagem. Para ilustrar tais momentos, escolheu-se o episódio de construção do conceito de histórias de aventura. Os objetivos das estratégias metodológicas recaíram sobre a identificação de pontos de vista dos participantes surdos, além da investigação de conhecimentos prévios e estimulação para tomadas de posições em relação ao tema discutido, para que se apropriassem de conceitos até então desconhecidos.

Para trabalhar o gênero literário narrativa de aventura, antes de tudo, era fundamental que os participantes surdos se apropriassem dos conceitos básicos desse gênero. Então, houve a necessidade de buscar elementos que contribuíssem para a construção desse conceito, indo além da simples datilologia da palavra aventura, e do sinal em Libras.

Primeiramente, apresentou-se um vídeo em libras, Aprende a escrever na areia ${ }^{7}$, criando um modelo de narrativa de aventura, para nortear as discussões para a construção do conceito. Em seguida, os pesquisadores exibiram trechos de famosos filmes de aventura ( $A$ múmia $^{8}$, Indiana Jones ${ }^{9}$, Piratas do caribe $^{10}$ ), conhecidos pelos participantes, para então ser

\footnotetext{
${ }^{6}$ HOLEINONE, Peter. As sete viagens de Simbad, o marujo e outras histórias. Tradução: Denise Perrotti. São Paulo: Paulinas, 1998.

${ }^{7}$ BRASIL. Ministério da Educação. Instituto Nacional de Educação de Surdos. Contando Histórias em Libras V. 9

${ }^{8}$ Filme: A Múmia. Titulo Original: The Mummy - Ano de Lançamento: 1999 - Direção: Stephen Sommers, João Jardim e Lucy Walker.

9 Filme: Indiana Jones, Os Caçadores da Arca Perdida. Título Original: Raiders of the Lost Ark-Ano de Lançamento: 1981 - Direção: Steven Spielberg. Distribuidor: PARAMOUNT PICTURES.
} 
convocado o sentido/experiência de história de aventura, de modo a elucidar experiências anteriores sobre a temática, facilitando a construção de conceitos, adotando-se, para tanto, estratégias da pedagogia visual e exploração de recursos imagéticos.

A construção do conceito de aventura foi realizada coletivamente. Os pesquisadores instigaram os participantes surdos a levantar elementos contidos nos dois tipos de textos, a narrativa em Libras e os filmes apresentados, relacionando-os com outras histórias conhecidas. Nesse processo, houve um diálogo entre todos os participantes da oficina, a partir do qual identificaram os elementos comuns aos vários textos, ou seja, elementos que compõem uma história de aventura (viagens, desafio, perigo, conflitos, entre outros).

Assim, os participantes chegaram em acordo quanto aos elementos comuns entre as histórias, e os pesquisadores puderam trazer o significado de história de aventura, apresentando o termo em Libras e em Língua Portuguesa, sedimentando, dessa forma, o conceito rastreado.

Ao final desse processo, os pesquisadores, a partir das conclusões elaboradas em conjunto, realizaram uma síntese retomando os elementos que eram necessários a uma história para que ela fosse considerada uma narrativa de aventura. Os pesquisadores, ainda, apresentaram mais uma vez o sinal de aventura, em Libras, e a palavra escrita, a fim de verificar se os participantes haviam realmente compreendido o conceito trabalhado.

\subsubsection{Análise do episódio}

O trabalho para a construção de novos conceitos foi realizado por intermédio da Libras, utilizando-se de alguns elementos em Língua Portuguesa, tal como a nomeação de pessoas, de objetos e de determinados conceitos, para facilitar a compreensão das futuras tarefas de leitura e escrita. Na atividade analisada acima, o português só foi utilizado para a nomeação do termo aventura, e dos títulos dos filmes, com a finalidade de invocar possíveis memórias visuais e convocar lembranças sobre elementos presentes nos filmes, que poderiam auxiliar na elaboração do conceito.

\footnotetext{
10 Filme: Piratas do Caribe - A Maldição do Pérola Negra. Título Original: Pirates of the Caribbean: the Curse of the Black Pearl - Ano de Lançamento: 2003 - Direção: Gore Verbinski. Distribuidor: Disney / Buena Vista.
} 
Não foi possível dizer se os participantes se apropriaram inteiramente do significado do termo, uma vez que a construção de conceitos não ocorre de forma linear e imediata, sendo atrelada, muitas vezes, a fatores individuais, a experiências anteriores e a relações que cada um dos sujeitos pode ou não estabelecer. Porém, quando um novo conceito é construído de maneira ativa (ou seja, quando o sujeito reflete sobre cada elemento antes da construção do conceito, ao invés de recebê-lo de forma passiva), por meio de trocas com seus pares, a compreensão torna-se mais efetiva e menor é a chance de se esquecer.

Vygotsky (2008) aponta o papel fundamental da linguagem no processo de construção do conhecimento, tendo em vista que a linguagem é responsável pela organização do pensamento e propicia formas ricas de interação com o outro, por meio de uma língua em comum. Durante este episódio, foi possível observar a relação entre sujeitos possibilitada pela linguagem, bem como a contribuição do diálogo com a primeira língua do sujeito surdo para a construção dos novos conceitos.

\subsection{A escrita coletiva - descrição do episódio}

Após aproximadamente seis encontros trabalhando com a introdução da história As sete viagens de Simbad, o marujo, por meio de narrativa em Libras, de leituras coletivas e do uso de imagens para a explicação de conceitos desconhecidos (como o conceito de embarcar em um navio, de mercador, de jardim, entre outros), os participantes surdos foram orientados a realizar atividades de reescritas coletivas da história apresentada.

A princípio foi pedido para que os participantes surdos narrassem a história em Libras, para que algum pesquisador a escrevesse em português, na lousa (num processo necessário de tradução). Entretanto, esse método pareceu confuso para os participantes, pois muitas vezes não entendiam o que estava escrito, pelo desconhecimento de determinados aspectos gramaticaistais como conjugação verbal, preposições, entre outros, e, nem sempre compreendiam essa escrita, mesmo quando era explicada, provavelmente, por não entenderem o processo ocorrido na transformação do que foi narrado em língua de sinais para o português.

Assim, os pesquisadores entenderam que a melhor estratégia seria que os participantes se revezassem para escrever na lousa uma parte da narrativa, com o auxílio dos demais surdos que permaneceriam em seus lugares. Após a escritura, se necessário, os pesquisadores corrigiriam o trecho, adequando-o ao português formal. No momento da escrita, os 
pesquisadores pouco intervinham, para não influenciar negativamente a troca de experiências entre o grupo de surdos, e quando o faziam, era para ajudá-los a lembrar de elementos presentes na história.

Dessa forma, a troca de experiências ocorreu com maior fluidez do que na tentativa anterior, porém, os participantes surdos tiveram alguns confrontos inevitáveis, como, por exemplo, em relação aos aspectos lexicais (a escolha da melhor palavra para expressar determinado conceito), ou sintáticos (quais elementos viriam antes, quais viriam depois na construção frasal), levando-os a intensas negociações quanto aos elementos relevantes dessa nova ordem sintática. O diálogo propiciou um maior entendimento dos conceitos de escrita, pois a troca de experiências parecia levá-los à reflexão sobre o próprio conhecimento e, por vezes, mudavam de opinião para chegar a novas formas de escrever.

Após o término da escrita de um trecho por um dos participantes surdos, em interação com os outros, os pesquisadores questionavam os participantes sobre a norma formal da escrita do português, e se o trecho escrito respeitava ou não essas normas, tencionando-os para a reflexão sobre o texto escrito. Nesse momento, os pesquisadores alteravam o texto, adequando-o às normas gramaticais, procurando, porém, alterar o mínimo possível a produção escrita, para não modificar o sentido original dado pelos surdos.

Abaixo, segue um exemplo da realização do processo apresentado. A primeir afrase é o texto produzido pelos participantes coletivamente e a segunda, após negociação entre o grupo e a intervenção dos pesquisadores, para adequá-la à gramática formal do português.

Ele viu os homens roupas elegante, pajens dar doces e bebinda os pessoas

Ele viu os homens com roupas elegantes e pajens dando doces e bebidas a eles.

\subsubsection{Análise do episódio}

É possível observar, no trecho acima, o quanto são utilizados os recursos da língua de sinais para a aquisição de uma nova língua. A estrutura gramatical construída pelos participantes surdos assemelha-se muito àquela utilizada em sua língua de comunicação. Por isso, é fundamental que as demais línguas sejam ensinadas com base na língua da construção de conceitos, pois, como afirma Peixoto (2006), o sujeito sempre recorre a ela para a aprendizagem. 
Os exercícios de escrita coletiva propiciaram aos participantes um momento de reflexão e criou a possibilidade de repensar a escrita da Língua Portuguesa. Os alunos surdos que observavam procuravam auxiliar o colega que estava escrevendo, colaborando com sinais e a produção da datilologia da palavra (recurso mais utilizado pelos participantes que possuíam um domínio maior do português) e, em conjunto, resgatavam parte da história e os modos de registrá-la em português.

As estratégias utilizadas contribuíram para a aprendizagem do português e para o próprio desenvolvimento da Libras pelos sujeitos surdos. Como aponta Vygotsky (2008), o conhecimento é construído pela mediação da linguagem, e essa é construída socialmente, por meio de trocas e negociações dialéticas com o outro. Assim, uma estratégia pedagógica que propicia tal troca entre seus pares traz uma grande contribuição para a aquisição de conceitos que se propõem a ensinar.

Realizando um trabalho semelhante, Guarinello (2007, p. 143) mostra que

\begin{abstract}
As atividades com a escrita devem privilegiar a dimensão discursiva da linguagem, envolvendo a interação professor-aluno, terapeuta-paciente. O professor/terapeuta deve ser o orientador, o mediador, o parceiro e o cúmplice na construção dessa língua, deixando o surdo livre para formular hipóteses até chegar à escrita convencional socialmente valorizada.
\end{abstract}

Faz-se necessário ressaltar a importância da interação entre os próprios participantes surdos que, ao compartilharem experiências semelhantes com o uso do português, sentem-se mais à vontade para as trocas dialógicas, já que não há uma hierarquização de conhecimentos. Tal fato facilita o processo, pois quando é o próprio parceiro surdo que faz alguma pergunta, parece haver menor preocupação com erro na resposta, em relação à mesma situação envolvendo os participantes ouvintes.

Para que os participantes surdos iniciassem a produção escrita, houve, por parte dos pesquisadores, a preocupação de que tal processo ocorresse de maneira contextualizada e significativa. Dessa forma, antes que o processo fosse iniciado, houve momentos de debate sobre a temática proposta, apresentação e discussão do texto trabalhado, primeiro em Libras, depois em português, e só após esse momento se iniciou a reescrita coletiva. Ou seja, a prática da reescrita do texto só teve início após se garantir conhecimentos de como se escreve um texto, conhecimentos esses que se adquirem a partir de práticas de leitura. Com isso, foram asseguradas condições para que os surdos se tornassem "realmente leitores e escritores e não 
apenas codificadores e decodificadores dos símbolos gráficos" (KARNOPP e PEREIRA, 2012, p. 132).

\section{CONSIDERAÇÕES FINAIS}

Com o desenvolvimento desta pesquisa foi possível compreender o papel que a língua de sinais tem para a construção dos conhecimentos, principalmente para a aquisição de outra língua. Frente às necessidades sociais, é indispensável que o surdo aprenda a língua majoritária, na modalidade escrita, da sociedade na qual está inserido. Porém, essa aprendizagem só ocorrerá efetivamente por meio de uma língua de sinais e das trocas dialógicas entre seus usuários. Nesse sentido, é importante que o professor de português de alunos surdos tenha, além do domínio pleno dessas duas línguas, uma metodologia adequada que resulte em uma prática pedagógica que propicie espaço dediálogo para a construção dos conhecimentos, valendo-se, em suas estratégias de ensino, de recursos visuais para a elaboração dos conceitos em estudo.

Dessa forma, o professor deve fazer uso de recursos pautados na visualidade, explorando a potencialidade e o interesse visual de seu aluno. As aulas devem ser planejadas com a utilização de imagens que facilitam a compreensão conceitual, buscando elucidar memórias que possam contribuir para o seu entendimento.

As estratégias pedagógicas analisadas durante as oficinas tiveram como objetivo essas construções de maneira que a Libras obtivesse um papel de destaque nesse espaço, e os pesquisadores se valeram de recursos visuais com a função de invocar registros de memórias anteriores, e trazer à tona conceitos já adquiridos, ou a criação de novos conceitos. Tais estratégias possibilitaram a aprendizagem dialógica entre todos os participantes, tendo como base as trocas de experiências para a construção de um conhecimento coletivo, antes da construção individual, destacando o papel das interações sociais para a aprendizagem.

Antes do desenvolvimento dos textos em português sempre houve uma preocupação com a contextualização da temática trabalhada, para que os estranhamentos que emergissem se dessem somente por conta da falta de experiência com uma língua escrita, e não pelo desconhecimento do tema.

É importante salientar que o planejamento das oficinas não foi fechado e as estratégias didáticas adotadas sofreram alterações ao longo do processo de ensino, em conformidade com 
as respostas dos participantes, objetivando a melhor aprendizagem do conteúdo ensinado. Uma estratégia não bem sucedida referiu-se ao processo de escrita coletiva, no qual os pesquisadores escreveriam na lousa o que era dito em Libras pelos participantes surdos. Tal processo mostrou-se confuso aos participantes, pois os pesquisadores já escreviam o português de maneira correta, não permitindo que os alunos entendessem o processo de transformação da Libras em português escrito. No entanto, quando se solicitou que os próprios surdos escrevessem o texto negociado entre eles, o processo de significação tornouse mais claro.

Em relação à continuidade das oficinas, pode-se dizer que há dois desafios a serem superados: a necessidade de serem criadas estratégias para aumentar a assiduidade dos participantes surdos e para a continuidade das atividades de leitura e de escrita fora do espaço da oficina. Quanto ao segundo desafio, Fernandes (2006) aponta que para aprender a ler e a escrever é necessário que se tenha experiências de prática de leitura e de escrita de maneira significativa. Isso ocorre durante os encontros, entretanto, as poucas horas semanais dedicadas a tais atividades não se mostram suficientes para o desenvolvimento pleno dessas capacidades. Como muitas vezes um conceito trabalhado em um encontro não é retomado durante a semana, ele acaba sendo esquecido, precisando ser recobrado no encontro seguinte. Dessa maneira, a tarefa dos pesquisadores consiste em criar novas estratégias e procedimentos que levem os participantes surdos a momentos de leitura e de escrita em outros contextos e horários.

A partir de uma reflexão sobre o processo de educação de alunos surdos, conclui-se que o histórico de defasagem na educação desses alunos tem ligação direta com o processo de escolarização no qual estão inseridos, o qual, na maioria das vezes, não atende às suas demandas linguísticas, nem tem o cuidado em favorecer a sua aprendizagem. Porém, tal histórico também é reflexo da falta de oportunidade de interação social com a língua de sinais, refletindo poucas oportunidades de letramento por não haver uma língua significativa em comum com os que estão a sua volta. Assim, a apropriação de sentido torna-se limitada, pois os alunos surdos só terão como base as informações visuais presentes. Dessa forma, é fundamental que as estratégias pedagógicas voltadas aos alunos surdos propiciem oportunidades efetivas para o desenvolvimento da linguagem, privilegiando ambientes em que ocorram trocas dialógicas, com uma língua que os beneficie para a aquisição do 
conhecimento, com o intuito de reduzir a defasagem educacional em relação a seus colegas ouvintes.

\title{
THE ENGLISH TEACHING AS A SECOND LANGUAGE FOR DEAF: TEACHING STRATEGIES
}

\begin{abstract}
Historically the difficulties of deaf students in relation to reading and writing skills were attributed to some causes inherent to deafness, however, currently, it is known that these difficulties occur because of a lack of consideration during the process of teaching and learning, of the deaf language specificities. Thus, the vast majority of deaf people, young and old, had no schooling that had respected these specificities. Therefore, this study aims to describe and analyze pedagogical strategies for the teaching of written Portuguese as a second language, from the construction of knowledge in Libras, in workshops for graduated deaf students in the literacy levels of basic education. The activities of the workshops were documented by video recordings and record in field diaries. Based on the conceptual framework of cultural-historical approach, this study demonstrated the importance of the relationship between researchers and deaf participants offered by language, constituting a space for communication, training and development of individuals. The results indicated that the use of Libras as language of instruction in these areas is critical to the construction of concepts and acquisition of knowledge in reading and writing, as well as appropriated teaching and informed in pictorial resources favored dialogical exchange, facilitating the understanding for deaf people.
\end{abstract}

Keywords: Portuguese for Deaf; Teaching Strategy; Bilingual Approach

\section{LA ENSEÑANZA DEL PORTUGUÉS COMO SEGUNDA LENGUA PARA SORDOS: ESTRATEGIAS DIDÁCTICAS}

\section{Resumen}

Históricamente, las dificultades del alumno sordo en relación con el aprendizaje de la lectura y la escritura fueron atribuidas a causas propias de la sordera, sin embargo, actualmente, se tiene conocimiento de que esas dificultades ocurren por no tener en consideración, sus 
especificidades lingüísticas durante el proceso de enseñanza y aprendizaje. De esta forma, la gran mayoría de los sordos, jóvenes y adultos, no tuvieron una escolarización que respetase tales especificidades. Por lo tanto, este trabajo tiene como objetivo describir y analizar las estrategias pedagógicas para la enseñanza del portugués escrito, como segunda lengua, a partir de la construcción de conocimientos en Libras, en talleres para alumnos sordos egresados de las etapas de alfabetización de la educación básica. Las actividades de los talleres fueron documentadas por medio de vídeo-grabaciones y de registro en diarios de campo. Fundamentados nuestros presupuestos teóricos de abordaje histórico-cultural, el presente estudio focalizó la importancia de las relaciones entre los investigadores y los participantes sordos propiciadas por el lenguaje, constituyéndose en espacio de comunicación, formación y constitución de sujetos. Los resultados indicaron que el uso de Libras como lengua de instrucción en estos espacios es fundamental para la construcción de conceptos y la adquisición de conocimientos en lectura y escritura, así como las didácticas apropiadas y basadas en recursos pictóricos favorecieron los intercambios dialógicos, facilitando la comprensión por los sujetos sordos.

Palabras claves: Lengua Portuguesa para Sordos; Estrategias Didácticas; Enfoque Bilingüe

\section{REFERÊNCIAS}

BAKHTIN, Mikail. Marxismo e Filosofia da Linguagem. 13ªed. São Paulo: Hucitec, 2009.

BRASIL. Decreto $N^{\circ}$ 5.626. Regulamenta a Lei $\mathrm{n}^{\circ}$ 10.436, de 24 de abril de 2002, que dispõe sobre a Língua Brasileira de Sinais-Libras, e o art.18 da Lei n ${ }^{\circ} 10.098$, de 19 de dezembro de 2000. Publicado no Diário Oficial daUnião em 22/12/2005.

BRASIL. LEI Nº10.436. Dispõe sobre a Língua Brasileira de Sinais-Libras e dá outras providências. Publicada no Diário Oficial daUnião em 24/04/2002.

CAMPELlO, Ana Regina e Souza. Pedagogia Visual/Sinal na Educação dos Surdos. In: QUADROS, R. M.; PERLIN, G. (orgs.). Estudos Surdos II. Petrópolis: AraraAzul, 2007. p.100-131.

FERNANDES, Sueli. Letramento na educação bilíngue para surdos. In: BERBERIAN, A. P.; ANGELIS, C. C.M. de; MASSI, G. (orgs.). Letramento: referências sem saúde e educação. São Paulo: Plexus, 2006.

FREITAS, Maria Teresa Assunção. A pesquisa de abordagem histórico-cultural: um espaço educativo de constituição de sujeitos. Revista Teias, Rio de Janeiro: ProPed/UERJ, v.10, 
n.19, 2009. Disponível em:

http://www.periodicos.proped.pro.br/index.php/revistateias/article/view/381/362. Acesso em 25/03/2015.

GÓES, M. C. R.; TARTUCI, D.. Alunos surdos e experiências de letramento. In: LODI, A. C. B.; MÉLO, A. D. B. de ; FERNADES, E (Orgs.). Letramento, bilinguismo e educação de surdos .Porto Alegre: Mediação, 2012.

GUARINELLO, Ana Cristina.O papel do outro na escrita de sujeito ssurdos. São Paulo: Plexus, 2007.

GUARINELLO, Ana Cristina. Letramento e linguagem nas práticas com sujeitos surdos. In: BERBERIAN,A. P.; ANGELIS, C. C.M. de; MASSI, G.(orgs.) .Letramento: referência ssem saúde e educação. São Paulo: Plexus, 2006. p. 348-367.

KARNOPP, Lodenir Becker, PEREIRA, Maria Cristina da Cunha. Condições de leitura e de escrita na educação de surdos. In: LODI, A. C. B.; MÉLO, A. D. B. de; FERNANDES, E (Orgs.). Letramento, bilinguismo e educação de surdos. Porto Alegre: Mediação, 2012.

LACERDA, Cristina Broglia Feitosa de. Um pouco da história das diferentes abordagens na educação dos surdos. Cadernos Cedes 46, Campinas: UNICAMP; Campinas: Papirus, v.46, p. 68-80, 1998.

LACERDA, C. B. F.; LODI, A. C. B. A inclusão escolar bilíngue de alunos surdos: princípios, breve histórico e perspectivas. In: LODI, A.C.B.; LACERDA, C. B. F (Orgs.). Uma escola, duas línguas: letramento em língua portuguesa e língua de sinais nas etapas iniciais de escolarização. Porto Alegre: Editora Mediação, 2014.

LACERDA, C. B. F.; SANTOS, L. F. CAETANO, J. F.. Estratégias Metodológicas para o ensino de alunos surdos. In: LACERDA, C, B. F. de; SANTOS, L. F (Orgs.). Tenho um aluno surdo, e agora? Introdução à Libras e educação de surdos. São Carlos: EdUFSCar, 2013.

LODI, Ana Claudia Balieiro. A leitura como espaço discursivo de construção de sentidos: Oficinas com surdos. 2004, 282f. Tese (Doutorado em Linguística Aplicada e Estudos da Linguagem), Pontifícia Universidade Católica de São Paulo, São Paulo.

PEIXOTO, Renata Castelo. Algumas considerações sobre a interface entre a língua brasileira de sinais (Libras) e a língua portuguesa na construção inicial da escrita pela criança surda. Cadernos Cedes, Campinas: UNICAMP; Campinas: Papirus, v. 26, n. 69, p. 205-229, maio/ago. 2006. Disponível em: Acesso em: 25/03/2015.

SANTOS, Lara Ferreira dos. O instrutor surdo em uma escola inclusiva bilíngue: sua atuação junto aos alunos nos espaços da oficina de língua brasileira de sinais. 2007. Dissertação (Mestrado em Educação), Universidade Metodista de Piracicaba. 
SOARES, Magda. Novas Práticas de leitura e escrita: letramento na cibercultura. Educação e Sociedade, Campinas, vol.23, n.81, p.143-160, dez. 2002. Disponível em:< http://www.scielo.br/pdf/es/v23n81/13935>. Acesso em: 25/03/2015.

SOUZA NETO, Manuel Fernandes. O ofício, a oficina e a profissão: reflexões sobre o lugar social do professor. Cadernos Cedes, Campinas: UNICAMP; Campinas, vol. 25, n.66, p.249, maio/ago. 2005. Disponível em:

<http://www.scielo.br/pdf/ccedes/v25n66/a07v2566.pdf> Acesso em: 20/02/2015.

VYGOTSKY, Lev Semenovich. Pensamento e Linguagem. Trad. Jefferson Luiz Camargo. São Paulo: Martins Fontes, 4. a ed., 2008.

VYGOTSKY, Lev Semenovich. A formação social da mente. Trad. José Cipollla Neto; Luiz Silveira Menna Barreto; Solange Castro Afeche. São Paulo: Martins Fontes, 6. ${ }^{\text {e ed., }}$ 1998. 